\title{
Comparative study of diclofenac suppository with tramadol suppository in addition to acetaminophen for post caesarian analgesia
}

\author{
Reetu Hooda $^{1}$, Prachi Pathak ${ }^{1 *}$, Rahul Chavhan ${ }^{2}$ \\ ${ }^{1}$ Department of Obstetrics and Gynecology, Pt. B.D. Sharma PGIMS Rohtak, Haryana, India \\ ${ }^{2}$ Department of Cardiovascular Radiology and Endovascular Interventions, AIIMS, New Delhi, India
}

Received: 23 February 2020

Accepted: 11 March 2020

\author{
*Correspondence: \\ Dr. Prachi Pathak, \\ E-mail: richas.kpathak@gmail.com
}

Copyright: $₫$ the author(s), publisher and licensee Medip Academy. This is an open-access article distributed under the terms of the Creative Commons Attribution Non-Commercial License, which permits unrestricted non-commercial use, distribution, and reproduction in any medium, provided the original work is properly cited.

\begin{abstract}
Background: Pain after emergency and elective caesarean section may adversely affect patient's recovery and breastfeeding initiation. The aim of present study was to compare the analgesic efficacy of diclofenac suppositoryintravenous acetaminophen (APAP) combination, tramadol suppository-intravenous APAP combination and intravenous APAP alone for postoperative pain relief after caesarean section.

Methods: We designed a randomized double-blind control study. Three hundred parturient scheduled for caesarean section were randomized to receive diclofenac rectal suppository $(100 \mathrm{mg})$, tramadol rectal suppository $(100 \mathrm{mg})$ or glycerin rectal suppository in Group A, B and C respectively (100 parturient in each group). All the women routinely received $1000 \mathrm{mg}$ acetaminophen intravenously. Assessment of pain was done using a visual analogue scale (VAS) at $0,1,6,12,18$ and 24 hours. injection Pentazocine $0.3 \mathrm{mg} / \mathrm{kg}$ IV was given as rescue analgesia when VAS score $>30$.

Results: The mean VAS score was significantly higher in Group C as compared to Group A and Group B (p value $<$ 0.001). This suggests better efficacy of multimodal treatment as compared to monotherapy. Group A as compared to Group B showed better efficacy in term of VAS score at 12 and 18 hours $(p=0.05, p=0.02$ respectively).

Conclusions: We found that when controlling for socio-demographic characteristics, combination of either diclofenac or tramadol suppository with acetaminophen has significantly better results when compared with monotherapy of acetaminophen alone in post-operative analgesia after caesarean section. However, the combination of diclofenac suppository has proved to be superior in comparison to tramadol suppository.
\end{abstract}

Keywords: Caesarean section, Diclofenac, Multimodal, Pain, Tramadol

\section{INTRODUCTION}

A caesarean section is inevitable in cases where the baby or mother are at risk in a vaginal delivery. Increased use of caesarean delivery has been ascribed to the liberalization of indications for foetal distress as well as elective repeat sections. The common indications for caesarean section include non-reassuring foetal status, failure to progress, cephalopelvic disproportion and malpresentation and prior uterine surgery. ${ }^{1}$ Caesarean section is one of the most commonly performed surgical operations worldwide at present. International health community has considered ideal rate of caesarean section of $10-15 \%$. Average caesarean section rate in India is $12 \%$ in public institutions and much higher $(28 \%)$ in private sectors. ${ }^{2}$ Just like other major surgical procedures, caesarean delivery may lead to severe postoperative pain and discomfort and it is a well-documented fact that the inadequately controlled pain is deleterious to maternal health and can lead to numerous postoperative complications. Adequate pain control after caesarean section is necessary for early mobilization of mother and to take care of her new-born as early as possible. ${ }^{3}$

Untreated surgical pain may result in maternal complications like basal atelectasis due to reduced 
ventilation and DVT as a result of delayed ambulation. In addition, early ambulation may also improve wound healing. ${ }^{4}$

The unimodal approach of pain management usually leads to inadequate pain control because in most of the cases the maximum dose of the drug is not used in fear of adverse effects.

In light of multifactorial mechanism of pain, multimodal analgesia with drugs that have different mechanisms of action, have been seen to potentiate the overall analgesic effect.

Therefore, a multimodal approach to provide adequate postoperative analgesia is gaining popularity these days. A stepwise approach using a multimodal combination of agents i.e., the use of two or more pain medications having different mechanisms of action, can enable obstetrician to effectively individualize pain management for women in the postpartum period. Several case series are present in literature supporting multimodal approach of pain management. ${ }^{5,6}$

Provision of effective post caesarean pain relief with minimal side effects is major concern for an obstetrician. Both diclofenac and tramadol have been used in different studies for post-operative analgesia but there is paucity in literature comparing diclofenac rectal suppository with tramadol suppository in addition to intravenous APAP for post caesarean pain relief. Hence, the present study had been envisaged for effective and safe post-operative analgesic regimen after caesarean section.

The aim of present study was to compare the analgesic efficacy of diclofenac suppository - intravenous APAP combination, tramadol suppository - intravenous APAP combination and intravenous APAP alone for postoperative pain relief after caesarean section.

\section{METHODS}

This was a randomized double-blind control study done on three hundred parturient scheduled for caesarean section in the department of obstetrics and gynaecology at Pt. B.D. Sharma PGIMS Rohtak (Haryana, India). Women who were scheduled for elective and emergency caesarean section under spinal anesthesia were included in the study. Women with known allergy to any of the study drugs, those having acute cardiac, renal, liver or respiratory diseases and those undergoing caesarean section in the second stage of labour (e.g. after deep transverse arrest) were excluded from study. The group allocation was done by using computer-generated randomization (randomizer.org).

Group A received diclofenac rectal suppository (100 mg), Group B received tramadol rectal suppository $(100 \mathrm{mg})$ and Group $\mathrm{C}$ women received glycerin rectal suppository. All the women routinely received $1000 \mathrm{mg}(100 \mathrm{ml}$ bottle) APAP intravenously over 15-20 minutes. In the postoperative period the first dose was given in the recovery room and was repeated every eight hour for 24 hours.

Assessment of pain was done using a visual analogue scale (VAS). The baseline VAS score was taken at zero hour (zero hour was the time when the patient was shifted to recovery room). Then score was assessed postoperatively at $1,6,12,18$ and 24 hours. If the patient had pain score $>30$ on VAS scale. Injection Pentazocine $0.3 \mathrm{mg} / \mathrm{kg}$ IV was given as rescue analgesia.

Primary outcome measured were assessment of pain intensity in form of pain score using visual analogue score (VAS) and the need for rescue analgesia.

\section{Statistical analysis}

Data was analyzed at end of study. The quantitative variables in all three groups were expressed as mean $\pm \mathrm{SD}$ and compared using unpaired t-test between groups.

The qualitative variables were expressed as frequencies/ percentages and compared using Chi-square test. A pvalue $<0.05$ was considered statistically significant. Statistical package for social sciences (SPSS) version 22.0, IBM Corp Armonk, NY/USA was used for statistical analysis.

\section{RESULTS}

The mean age of women in group A was $24.88+3.89$ years, of Group B was $25.08 \pm 4.63$ years and of Group C was $25.77 \pm 4.47$ years $(p>0.05)$. Also, there was no statistically significant difference in other variables like BMI, haemoglobin, parity, mean gestational age, population distribution, socioeconomic status, neonatal outcome and type of LSCS (Table 1).

Mean VAS score was significantly higher ( $\mathrm{p}$ value < 0.001) in Group C as compared to Group A and Group B at various predetermined time intervals i.e. at 0 -hour, 1 hour, 6 hours, 12 hours, 18 hours and 24 hours. Mean VAS score was gradually decreasing over time in all three groups. At 12 hours and 18 hours Group B patients had significantly higher mean VAS score values as compared to Group A patients ( $p$ value $<0.05$ ). At 0 hour, 1 hour and 6 hours Group A versus Group B showed no significant difference (Table 2).

Only $2 \%$ of the study population in Group A and Group $B$ required rescue analgesia in the form of I.V. Pentazocin for adequate pain control. While on the contrary, in Group C 95\% women required rescue analgesia. The need for rescue analgesia was similar between Group A and B whereas a significantly higher women require rescue analgesia in Group $\mathrm{C}(\mathrm{p}$ value $<$ 0.001) (Table 3). 
Table 1: Baseline maternal characteristics and demographics.

\begin{tabular}{|c|c|c|c|c|}
\hline Variables & Group A & Group B & Group C & p value \\
\hline Age (years) & $24.88 \pm 3.89$ & $25.08 \pm 4.63$ & $25.77 \pm 4.47$ & $>0.05$ \\
\hline $\operatorname{BMI}\left(\mathrm{kg} / \mathrm{m}^{2}\right)$ & $24.75 \pm 2.85$ & $24.44 \pm 3.16$ & $24.27 \pm 2.62$ & $>0.05$ \\
\hline \multicolumn{5}{|l|}{ Haemoglobin (gm/dl) } \\
\hline$<9$ & $14.00 \%$ & $16.00 \%$ & $17.00 \%$ & \multirow{3}{*}{$>0.05$} \\
\hline $9-11$ & $60.00 \%$ & $48.00 \%$ & $56.00 \%$ & \\
\hline $11-13$ & $26.00 \%$ & $36.00 \%$ & $27.00 \%$ & \\
\hline \multicolumn{5}{|l|}{ Gravida } \\
\hline Primi & $51.00 \%$ & $55.00 \%$ & $41.00 \%$ & \multirow{2}{*}{$>0.05$} \\
\hline Multi & $49.00 \%$ & $45.00 \%$ & $59.00 \%$ & \\
\hline Gestation age (weeks) & $38.96 \pm 1.5$ & $38.73 \pm 1.47$ & $38.69 \pm 1.5$ & $>0.05$ \\
\hline \multicolumn{5}{|c|}{ Population distribution } \\
\hline Rural & $19.00 \%$ & $16.00 \%$ & $24.00 \%$ & \multirow{2}{*}{$>0.05$} \\
\hline Urban & $81.00 \%$ & $84.00 \%$ & $76.00 \%$ & \\
\hline \multicolumn{5}{|l|}{ Socioeconomic status } \\
\hline Lower & $14.00 \%$ & $7.00 \%$ & $7.00 \%$ & \multirow{3}{*}{$>0.05$} \\
\hline Lower middle & $28.00 \%$ & $26.00 \%$ & $28.00 \%$ & \\
\hline Upper middle & $58.00 \%$ & $67.00 \%$ & $65.00 \%$ & \\
\hline \multicolumn{5}{|l|}{ Neonatal outcome } \\
\hline Mother side & $97.00 \%$ & $98.00 \%$ & $98.00 \%$ & \multirow{2}{*}{$>0.05$} \\
\hline NICU admission & $3.00 \%$ & $2.00 \%$ & $2.00 \%$ & \\
\hline \multicolumn{5}{|l|}{ Type of LSCS } \\
\hline Emergency & $92.00 \%$ & $93.00 \%$ & $92.00 \%$ & \multirow{2}{*}{$>0.05$} \\
\hline Elective & $8.00 \%$ & $7.00 \%$ & $8.00 \%$ & \\
\hline
\end{tabular}

Table 2: Pain assessment by VAS score.

\begin{tabular}{|c|c|c|c|c|c|c|c|c|c|}
\hline \multirow{2}{*}{ VAS score } & \multicolumn{2}{|c|}{ Group A } & \multicolumn{2}{|c|}{ Group B } & \multicolumn{2}{|c|}{ Group C } & \multicolumn{3}{|l|}{ p-value } \\
\hline & Mean & \pm SD & Mean & \pm SD & Mean & \pm SD & A versus B & A versus $C$ & $B$ versus $C$ \\
\hline 0 hours & 8.02 & \pm 0.2 & 8.02 & \pm 0.2 & 9.90 & \pm 0.44 & 0.500 & $<0.001$ & $<0.001$ \\
\hline 1 hours & 5.60 & \pm 0.9 & 5.40 & \pm 1.01 & 7.90 & \pm 0.44 & 0.070 & $<0.001$ & $<0.001$ \\
\hline 6 hours & 3.50 & \pm 0.96 & 3.58 & \pm 1.07 & 5.50 & \pm 0.96 & 0.290 & $<0.001$ & $<0.001$ \\
\hline 12 hours & 1.98 & \pm 0.6 & 2.22 & \pm 0.69 & 3.42 & \pm 0.91 & 0.005 & $<0.001$ & $<0.001$ \\
\hline 18 hours & 0.08 & \pm 0.39 & 0.32 & \pm 0.74 & 1.62 & \pm 0.89 & 0.002 & $<0.001$ & $<0.001$ \\
\hline 24 hours & 0.00 & \pm 0 & 0.02 & \pm 0.2 & 0.00 & \pm 0 & 0.159 & 0.159 & 0.159 \\
\hline
\end{tabular}

Table 3: Need for rescue analgesia.

\begin{tabular}{|l|llllll|l|}
\hline Rescue analgesia & \multicolumn{2}{c}{ Group A $(\mathbf{n}=\mathbf{1 0 0})$} & \multicolumn{2}{c|}{ Group B $(\mathbf{n}=\mathbf{1 0 0})$} & \multicolumn{2}{c|}{ Group C $(\mathbf{n}=\mathbf{1 0 0})$} & p value \\
\hline Required & $\mathbf{n}$ & $\mathbf{\%}$ & $\mathbf{N}$ & $\mathbf{\%}$ & $\mathbf{n}$ & $\mathbf{\%}$ & \\
\hline Not required & 2 & $2.00 \%$ & 2 & $2.00 \%$ & 95 & $95.00 \%$ & $<0.001$ \\
& 98 & $98.00 \%$ & 98 & $98.00 \%$ & 5 & $5.00 \%$ & $<0.001$ \\
\hline
\end{tabular}

\section{DISCUSSION}

The present study suggests better efficacy of multimodal therapy for pain control as compared to monotherapy. The mean VAS score was significantly higher ( $\mathrm{p}$ value $<$ 0.001 ) in Group C as compared to Group A and Group B at various predetermined time intervals i.e., at 0 -hour, 1 hour, 6 hours, 12 hours, 18 hours and 24 hours. Multimodal treatment given in both group A and group B showed an additive analgesic effect as the drugs had different mechanism of action and route of entry. This suggests better efficacy of multimodal treatment as compared to monotherapy (Figure 1).

Similar inference came out in a double-blind randomized controlled trial performed in 2008, they concluded that patients given a combination of diclofenac and APAP used 38\% less morphine compared to patients given APAP after caesarean section. ${ }^{7}$

A randomized controlled trial comparing two multimodal analgesic techniques in patients predicted to have severe 
pain after caesarean deliver (2015). A significant reduction of evoked pain score was observed where acetaminophen was used in addition to morphine. ${ }^{8}$

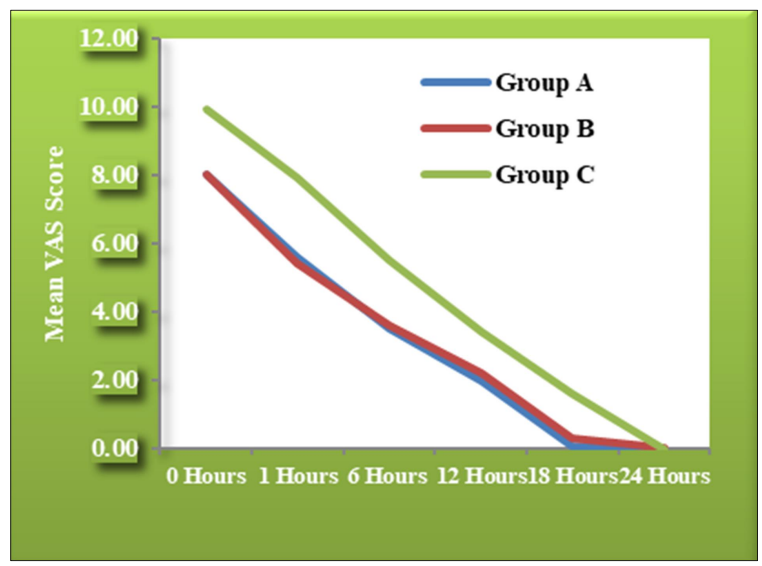

Figure 1: VAS score plot over time in three study groups.

There was gradual decrease in mean VAS score in the course of time in present study, suggesting normal physiological decrease of pain over time after an acute traumatic event. This finding is comparable to the VAS plot over time in a recent randomized double-blind study performed by Merrikhihagi S et al. ${ }^{9}$

On comparing group A and group B patients receiving different multimodal regimes, patients receiving diclofenac suppository + APAP combination showed better efficacy as compared to patients receiving tramadol suppository + APAP combination at 12 and 18 hours of treatment ( $\mathrm{p}$ value 0.002 ).

Darvish $\mathrm{H}$ et al concluded that IV APAP and Diclofenac suppository combination had a better efficacy in postoperative pain control and decreased requirement of additive analgesia compared to IV Meperidine ( $\mathrm{p}$ value $0.009) .^{10}$

According to a prospective nonrandomized study performed in 2015, Multimodal approach (Group I received IV paracetamol 1g 6 hourly, Group II received IM Diclofenac $75 \mathrm{mg} 8$ hourly and Group III a combination of both) using the agents with different mechanisms of action to achieve superior efficacy and decrease the need of opioids. Similar to present study they also concluded that balanced analgesia with a combination of NSAIDS and acetaminophen forms the preferred method for postoperative pain of caesarean section. ${ }^{11}$

Ong et al, also showed that using a combination of acetaminophen with an NSAID (various type and number of patients $n=6$ Ibuprophen, $n=8$ Diclofenac, $n=3$ Ketoprofen, $\mathrm{n}=1$ Ketorolac, $\mathrm{n}=1$ Aspirin, $\mathrm{n}=$
Tenoxicam, $\mathrm{n}=1$ Rofecoxib) analgesic compared to the separate use of each drug is more effective. ${ }^{12}$

A double-blind clinical trial showed that the combination of IV Acetaminophen and Diclofenac suppository has better and longer analgesic effects than sole use administration of each drugs. Like present study they also concluded that the combination therapy is able to provide a prolonged and effective analgesia for postoperative pain management of caesarean section with less side effects and stronger synergistic effects compared to other opioids. $^{8}$

In a similar comparative study performed by Hyllested et al, documented that the analgesic combination is better than acetaminophen as regards the pain score, supplemental analgesia and pain relief. ${ }^{13}$

The sample size of this study was small; hence it might be difficult to generalize the results, larger and multicentric trials are required for the same.

\section{CONCLUSION}

Combination of either diclofenac or tramadol suppository with acetaminophen has significantly better results when compared with monotherapy of acetaminophen alone in post-operative analgesia after caesarean section. However, the combination of diclofenac suppository has proved to be superior in comparison to tramadol suppository. This benefit was significantly higher in term of VAS score, early ambulation with or without support and initiation of breast feeding without support. The present study indicates a significant effect of concomitant use of intravenous acetaminophen and diclofenac suppository on pain severity reduction and early recovery after caesarean section, hence it is recommended.

Funding: No funding sources

Conflict of interest: None declared

Ethical approval: The study was approved by the Institutional Ethics Committee

\section{REFERENCES}

1. Pereira S, Portela F, Santos M, Machado J, Abelha A. Predicting type of delivery by identification of obstetric risk factors through data mining. Procedia Comput Sci. 2015;64:601-9.

2. Appropriate technology for birth. Lancet. 1985;2(8452):436-7.

3. Verstraete S, Van deVM. Post-cesarean section analgesia. Acta Anaesthesiol Belg. 2012;63:147-67.

4. Harper CM, Lyles UM. Physiology and complication after bed rest. J Am Geriatr Soc. 1988;36:1047-54.

5. Kehlet H, Dahl JB. The value of 'multimodal' or 'balanced analgesia' in postoperative pain treatment. Anesth Analg. 1993;77:1048-56.

6. Chan A, Dore CJ, Ramachandra V. Analgesia for day surgery. Evaluation of the effect of diclofenac 
given before or after surgery with or without bupivacaine infiltration. J Anaesth. 1996;51:592-5.

7. Munishankar B, Fettes P, Moore C, Mcleod GA. Adouble-blind randomized controlled trial of paracetamol, diclofenac or the combination for pain relief after cesarean section. Int J Obstet Anaesth. 2008;17:9-14.

8. Booth JL, Harris LC, Eisenach JC, Peter H. A randomized controlled trial comparing two multimodal analgesic techniques in patients predicted to have severe pain after cesarean delivery. Anesth Analg. 2016;122:1114-9.

9. Merrikhihaghi S, Farshchi A, Farshchi B, Farshchi S, Dorkoosh FA. Tramadol versus Diclofenac in pain management after cesarean section: a cost analysis study. J Pharm Pharm Sci. 2015;1(1):22-4.

10. Heidar D, Behrouz MA, Shali SMK, Tajik A. Analgesic efficacy of Diclofenac and Paracetamol vs Meperidine in cesarean section. Anesth Pain Med. 2014;4:e9997.

11. Taneja A, Kaur T, Sood IV. Comparative study on the effect of Paracetamol, Diclofenac and their
Combination in post operative pain relief of cesarean section. J K Sci. 2015; 17:30-2.

12. Ong CK, Seymour RA, Lirk P, Merry AF. Combining paracetamol (acetaminophen) with nonsteroidal anti-inflammatory drugs: a qualitative systematic review of analgesic efficacy for acute postoperative pain. Anesth Analg. 2010;110:117079.

13. Hyllested M, Jones S, Pedersen JL, Kehlet $\mathrm{H}$. Comparative effect of paracetamol, NSAIDs, or their combination in postoperative pain management: a qualitative review. Br J Anaesth. 2002;88:199-214.

Cite this article as: Hooda R, Pathak P, Chavhan R. Comparative study of diclofenac suppository with tramadol suppository in addition to acetaminophen for post caesarian analgesia. Int J Reprod Contracept Obstet Gynecol 2020;9:1372-6. 